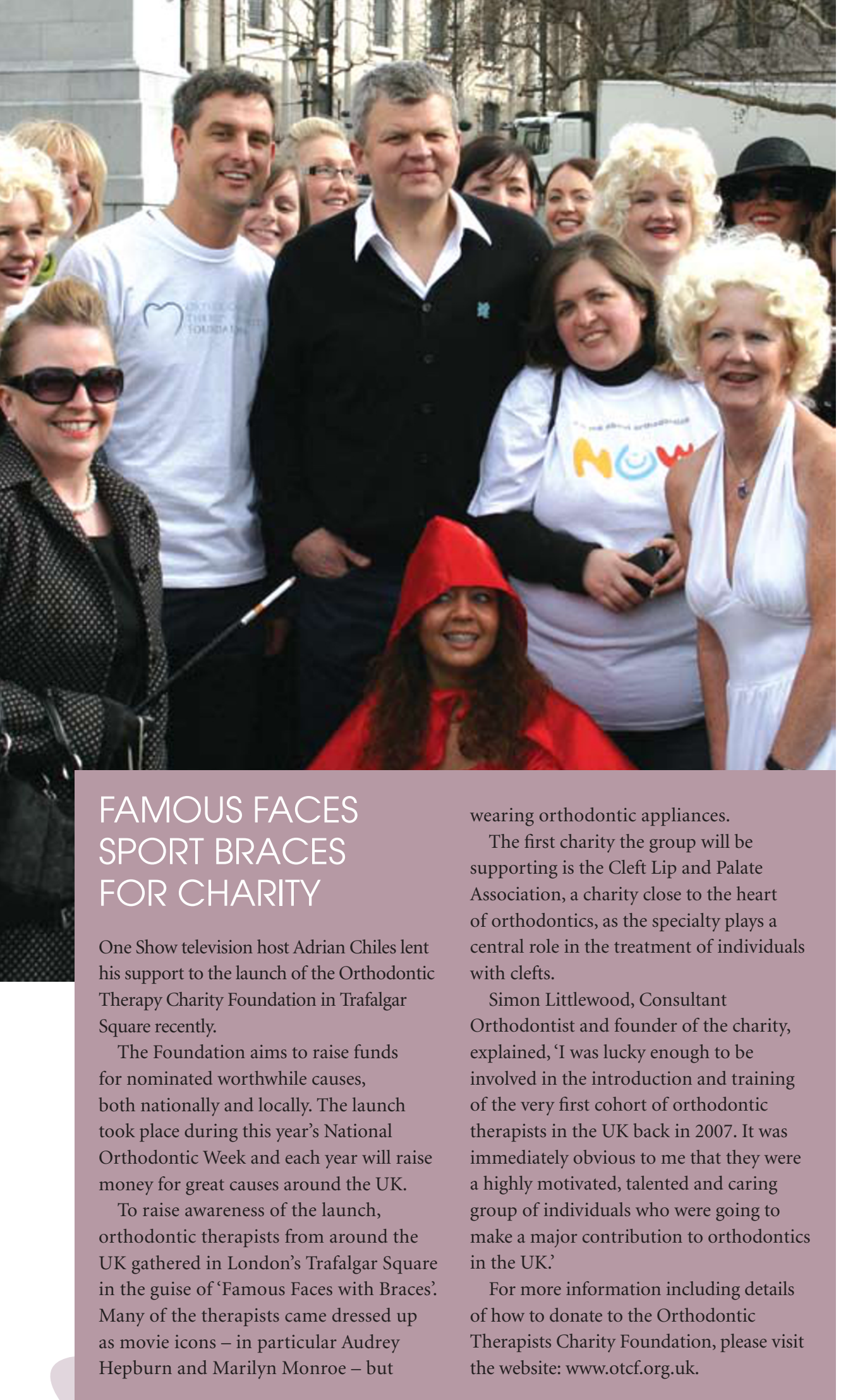

\section{CALL FOR DENTAL VOLUNTEERS FOR 2012 GAMES}

Organisers of the London 2012 Olympic and Paralympic Games are to recruit 70,000 volunteers in July 2010, which includes over 200 dental volunteers. Dentists and dental care professionals can apply directly to tony.clough@ Iondon2012.com to be added to the list of those expressing an interest in becoming a dental volunteer for the Olympic and Paralympic Games.

A Specialist Dental Service will be provided in the Polyclinic situated in the Athletes' Village in Stratford, East London. All shortlisted applicants will be interviewed and their skills and experience will influence successful applications, while also helping to determine at which venues (or Polyclinic) they are most appropriately based. All volunteers will need to commit to at least ten days.
HYGIENE EVENT TO BE HELD IN SCOTLAND

The International Symposium on Dental Hygiene (ISDH 2010) is set to take place in Glasgow from 1 to 3 July. Held under the auspices of the International Federation of Dental Hygienists, this

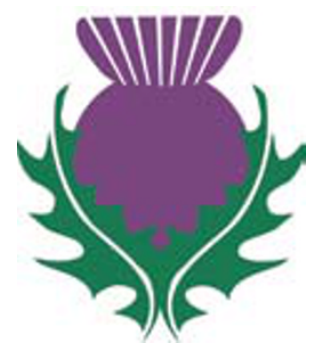
symposium occurs only every three years and is unlikely to return to the UK for some time.

There will be a packed scientific programme with international speakers, as well as workshops, presentations of research papers, a 65-stand exhibition, social events and many opportunities for networking.

Organised by the British Society of Dental Hygiene and Therapy (BSDHT), delegate rates are available for one, two or all three days and registrations will continue to be taken right up until 12 noon on 29 June. For more information contact the BSDHT on 01452886365 or enquiries@bsdht.org.uk, or see www.bsdht.org.uk.

\section{DLA SEES HEALTHY RETENTION FIGURES}

The Dental Laboratories Association

(DLA) has seen excellent retention

figures for 2010 demonstrating that DLA members value their membership to the Association.

The Association, which represents dental laboratory owners in the UK, retained $93 \%$ of its membership.

'We pride ourselves on supporting our members and delivering exceptional service and right now we're finding that our members need our support more than ever,' explained Richard Daniels, Chief Executive.

The DLA is also benefiting from increased interest with recruitment figures already being up 90\% compared with those for the whole of 2009.

The DLA's current focus is on promoting British dental technology and welcomes the recent GDC Standards on Commissioning and Manufacturing Dental Appliances, which outlines the extra responsibilities placed on registrants choosing to use the services of non-UK-registered dental technicians.

For further information contact 0115 9254888, email info@dla.org.uk or visit www.dla.org.uk. 